\title{
AUTOREN- UND PATENTREGISTER
}

Teil HII: $Q-Z$
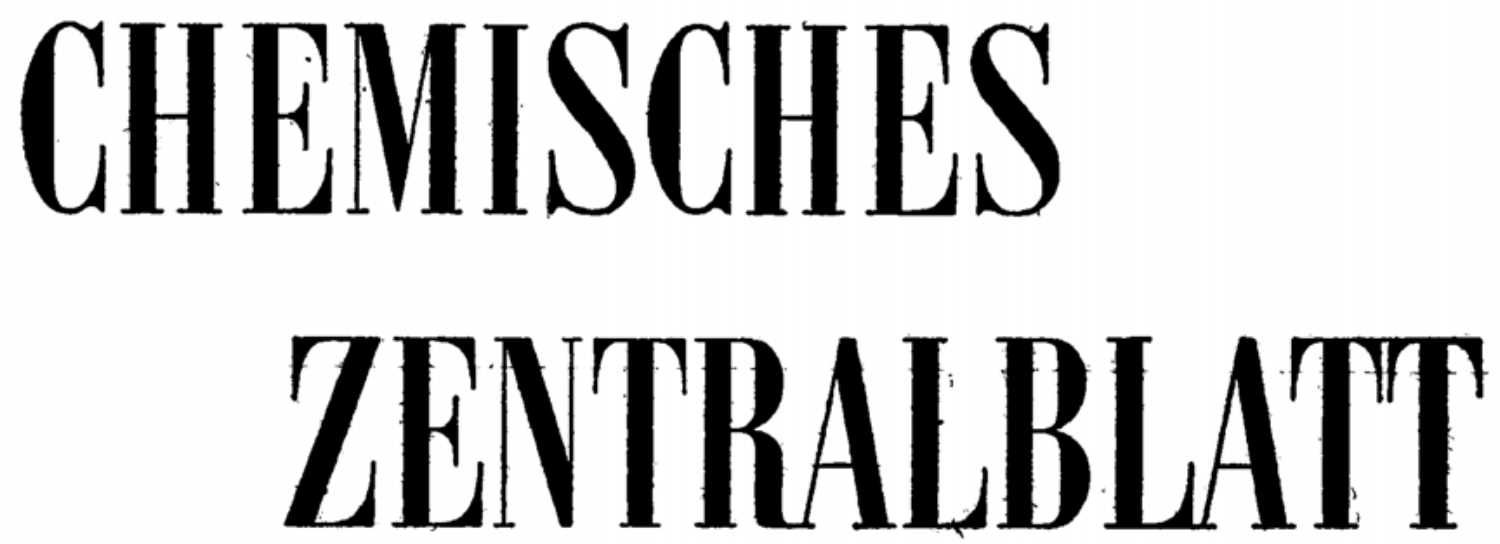

1830 gegründet

1897-1945 von der Deutschen Chemischen Gesellschaft fortgeführt

Herausgegeben im Auftrage

der Deutschen Akądemie der Wissenschaften zù Berlin,

der Chemischen Gesellschaft in der DDR,

der Akademie der Wissenschaften zu Göttingen

und der Gesells'chaft Deutscher Chemiker

von Prof. Dr. HeINRICH BERTSCH und Prof. Dr. Dr. h. c. WILHELM KLEMM

Chefredakteure

Dr. HELGA' VÖLZ und Dr.-Ing. CHRISTIAN WEISKE

138. JAHRGANG

1967 


\section{PERIODICA CHIMICA}

Verzeichnis der im Chemischen Zentralblatt referierten Zeitschriften mit den entsprechenden genormten Titelabkürzungen

Herausgegeben von Maximilian PAl̈cke und Alice Hawelek

Nachdruck der zweiten, neubearbeiteten Auflage

1961. X, 411 Seiten - gr. $8^{\circ}-$ Lederin $35,-$

NACHTRAG

1962. VI, 245 Seiten - gr. $8^{\circ}$ - Lederin $35,-$

Ein Urteil zur zweiten Auflage:

Die "Periodica Chimica” stellen nicht nur ein einfaches Verzeichinis der im "Chemischen Zentralblatt" bei den Referaten berücksichtigten Zeitschriften dar. Die Herausgeber haben sich die Mühe genommen, in der 2. Auflage auch alle seit 1930 erfolgten Titeländerungen und außerdem alle zeitweisen Unterbrechungen im Erscheinen jeder Zeitschrift aufzunehmen. Dadurch wird die rein literarische Arbeit vor allem bei ungenauen Quellenangaben wesentlich erleichtert. Zur besonderen Berücksichtigung müssen aber die bei jeder Zeitschrift angegebenen internationalen Titelabkürzungen empfohlen werden, da sonst immer wieder Irrtümer vorkommen. Alles in allem sind die "Periodica Chimica", die keineswegs nur auf die chemischen Zeitschriften beschränkt sind, sondern auch „Periodica" aus den anderen naturwissenschaftlichen Gebieten umfassen, ein zuverlässiger Wegweiser im einschlägigen wissenschaftlichen Schrifttum.

(Scientia Pharmaceutica)

\section{Verlag Chemie . CmbH \\ Akademie-Verlag · GmbH \\ 6940 Weinheim/Bergstr. \\ 108 Berlin}




\section{AUTOREN- UND PATENTREGISTER}

Teil III: Q-Z

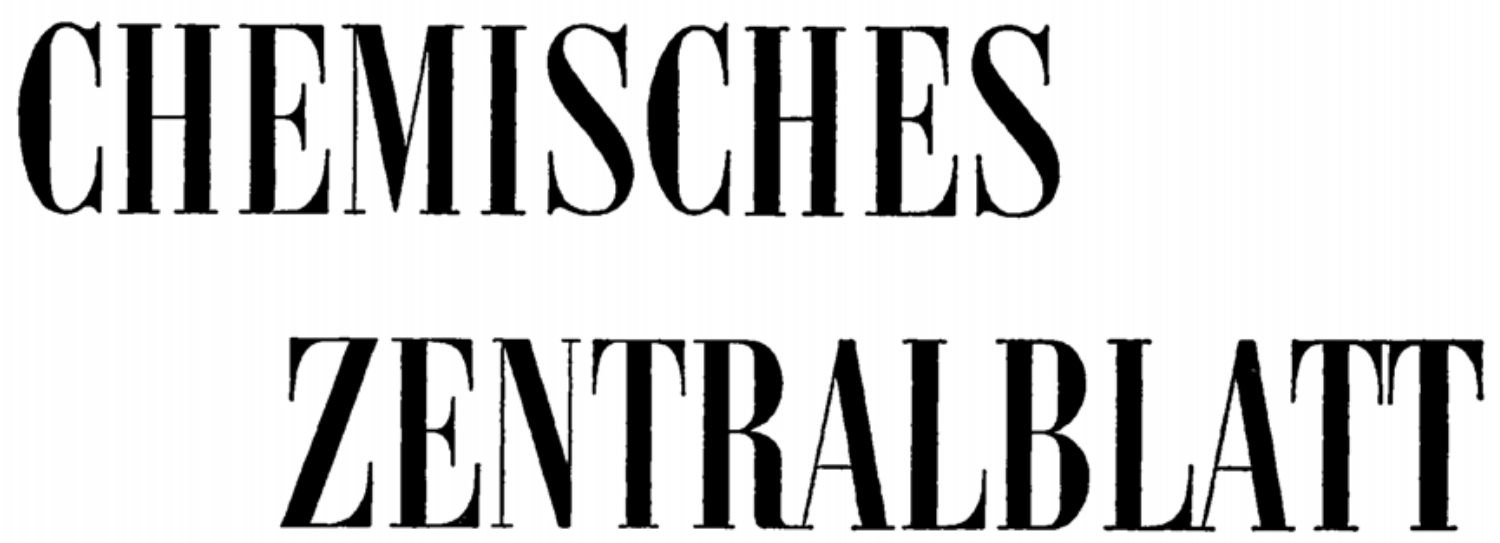

1830 gegründet

1897-1945 von der Deutschen Chemischen Gesellschaft fortgeführt

Herausgegeben im Auftrage

der Deutschen Akademie der Wissenschaften zu Berlin,

der Chemischen Gesellschaft in der DDR,

der Akademie der Wissenschaften zu Göttingen

und der Gesellschaft Deutscher Chemiker

von Prof. Dr. HEINRICH BERTSCH und Prof. Dr. Dr.h.c. WILHELM KLEMM

Chefredakteure

Dr. HELGA völZ und Dr.-Ing. CHRISTIAN WEISKE

138. JAHRGANG

1967 